\title{
Predictive model for wave-induced currents and 3D beach evolution based on FAVOR Method
}

\author{
Masamitsu Kuroiwa ${ }^{1}$, Mazen Abualtayef ${ }^{1}$, Tetsushi Takada ${ }^{1}$, Ahmed Khaled Seif $^{1,2}$ and Yuehi Matsubara ${ }^{1}$ \\ ${ }^{1}$ Department of Civil Engineering, Tottori University, Tottori, Japan \\ ${ }^{2}$ National Water Research Center, Cairo, Egypt
}

\begin{abstract}
The development of a numerical model using the fractional area/volume obstacle representation (FAVOR) method for predicting a nearshore current field bounded by complicated geometric shapes, and a three-dimensional (3D) beach evolution was described in this article. The $3 D$ model was first tested against three cases to simulate the nearshore current fields around coastal structures, a river mouth, and a large scale cusp bathymetry. Then, the morphodynamic model tests, which are adopting the nearshore current model, were applied for the computations of beach evolution around a detached breakwater and two groins. It was confirmed that the presented model associated with the FAVOR method was useful to predict the nearshore current field in the vicinity of the complicated geometric shapes. Finally, the model was applied to a tombolo formation in a field site of Kunnui fishery port, which is located in Hokkaido, Japan.
\end{abstract}

KEY WORDS: FAVOR method; Nearshore current; Beach evolution; Detached breakwater.

\section{INTRODUCTION}

As a result of increasing public interest in environmental issue more attention is now being paid to the coastal environment and humankind's impact on it. The root of understanding problems such as beach erosion and design of breakwaters is an accurate description of the underlying hydrodynamics and morphodynamics. There are two main problems with numerical simulation. Firstly, the underlying physics must be described in enough detail to capture the essential features of the flow. Secondly, the problem with numerical simulation concerns the algorithms used to approximate the solution of the flow model. The solvers presented in this article respect the underlying physics and address all these problems. There is one further issue concerning the numerical simulation method that relates to the gridding of the computational domain. Problems in coastal hydrodynamics often occur over complicated geometries with highly irregular coastlines, the presence of islands and complex harbor and breakwater configurations.

Classical numerical approaches based on Cartesian grids use crude saw-tooth (e.g. Chen et al. (2007) uses the diagonal Cartesian grids) or stair-step approximations to the boundaries of the domain, which lead to unnecessary solution errors. To overcome such errors, the FAVOR method proposed by Hirt and Sicilian (1985) was adopted in the

Corresponding author: Mazen Abualtayef

e-mail:mazen_tayef@yahoo.com model. Grid distortion problems are eliminated by using a grid composed of rectangular cells. Geometric boundaries are defined within this grid using a porosity technique in which the porosity has a zero value within obstacles and a unit value elsewhere.

The numerous 3D beach evolution models were proposed based on the depth-averaged or/and quasi-3D nearshore current model. We proposed the 3D beach evolution model that can compute the shoreline change (Kuroiwa et al., 2004). Furthermore, we investigated the applicability of the model against the morphodynamics around the river mouth (Kuroiwa et al., 2007). However, the accuracy of the hydrodynamic computation and the estimation of sediment transport rate near the shoreline and in the run-up area were insufficient when the direction of shoreline and of obstacles such as detached breakwaters and groins was inclined against the Cartesian coordinates.

The main goal of this study is to formulate and develop a new 3D numerical model to clarify the morphodynamics process with the association of the FAVOR method.

\section{NUMERICAL MODEL}

The presented model consists of hydrodynamic module for solving the wave and nearshore currents, sediment transport module, and water depth change computation module. The model utilizes the FAVOR technique in order to model complex geometric regions. The true volume of fluid 
method accurately tracks the sharp interface and does not compute the dynamics in the void or air regions. The portion of volume or area occupied by the obstacle in each cell is defined at the beginning of the analysis. The fluid fraction in each cell is also calculated. The continuity, momentum or transport equation of the fluid fraction is formulated using the FAVOR function. A finite difference approximation is used for the discretization of each equation. Unlike some finite element/volume or boundary fitting grid methods, this meshing technique does not require re-meshing and does not induce any mesh distortion during the transient analysis. Therefore, an accurate algorithm solution can easily be applied.

\section{Hydrodynamic module}

Wave field was determined using a multi-directional random wave model proposed by Mase (2000), which is based on the energy balance equation with energy dissipation terms due wave breaking and diffraction. The energy dissipation term was formulated by using Goda's breaking criterion and the Rayleigh distribution's assumption for the wave heights. In the wave computation, the JONSWAP spectrum and the Mitsuyasu angular spreading function were employed.

The nearshore current field was determined based on the depth-averaged model. The FAVOR method was used in this module. The equations of motion and the continuity equation are represented as follows:

$$
\begin{aligned}
& \frac{\partial U}{\partial t}+\frac{1}{V o l} U \frac{\partial A_{x} U}{\partial x}+\frac{1}{V o l} V \frac{\partial A_{y} U}{\partial y}=-g \frac{\partial \bar{\eta}}{\partial x} \\
& -\frac{1}{V o l} \frac{1}{\bar{\eta}+h}\left\{\frac{\partial A_{x} S_{x x}}{\partial x}+\frac{\partial A_{y} S_{y x}}{\partial y}\right\}+\frac{1}{V o l}\left\{\begin{array}{l}
\frac{\partial}{\partial x}\left(A_{x} v_{e} \frac{\partial U}{\partial x}\right)+ \\
\frac{\partial}{\partial y}\left(A_{y} v_{e} \frac{\partial U}{\partial y}\right)-F_{x}
\end{array}\right\}
\end{aligned}
$$

$$
\begin{aligned}
& \frac{\partial V}{\partial t}+\frac{1}{V o l} U \frac{\partial A_{x} V}{\partial x}+\frac{1}{V o l} V \frac{\partial A_{y} V}{\partial y}=-g \frac{\partial \bar{\eta}}{\partial y} \\
&-\frac{1}{V o l} \frac{1}{\bar{\eta}+h}\left\{\frac{\partial A_{x} S_{x y}}{\partial x}+\frac{\partial A_{y} S_{y y}}{\partial y}\right\}+\frac{1}{V o l}\left\{\begin{array}{l}
\frac{\partial}{\partial x}\left(A_{x} v_{e} \frac{\partial V}{\partial x}\right)+ \\
\frac{\partial}{\partial y}\left(A_{y} v_{e} \frac{\partial V}{\partial y}\right)-F_{y}
\end{array}\right\}
\end{aligned}
$$

$$
\frac{\partial \bar{\eta}}{\partial t}+\frac{1}{V o l}\left(\frac{\partial A_{x}(\bar{\eta}+h) U}{\partial x}+\frac{\partial A_{y}(\bar{\eta}+h) V}{\partial y}\right)=0
$$

where, $U$ and $V$ are the depth average horizontal velocities in $x$ and $y$ directions. $A_{x}$ and $A_{y}$ are the open area fraction. $V o l$ is the open volume fraction. $\bar{\eta}$ is the average surface water level. $h$ is the water depth. $g$ is the acceleration of gravity. $F_{x}$ and $F_{y}$ are the bottom shear stresses in x and y directions. $S_{i j}$ are radiation stresses solved by linear wave theory. $v_{e}$ is the eddy viscosity, which was estimated by the depth-average (M2D) model (Buttolph et al., 2006). The quantities such as excess momentum fluxes, eddy viscosities, bottom shear stresses were determined using the root-mean square wave height and peak period of frequency spectrum. The continuity and motion equations were solved using the finite difference method based on the coordinate definition as shown in Fig. 1. In the calculations, $A_{x}, A_{y}$ and $V o l$ are divided by the mean water depth. Instead of those fractions, $l_{x}, l_{y}$ and $A_{z}$ were used.
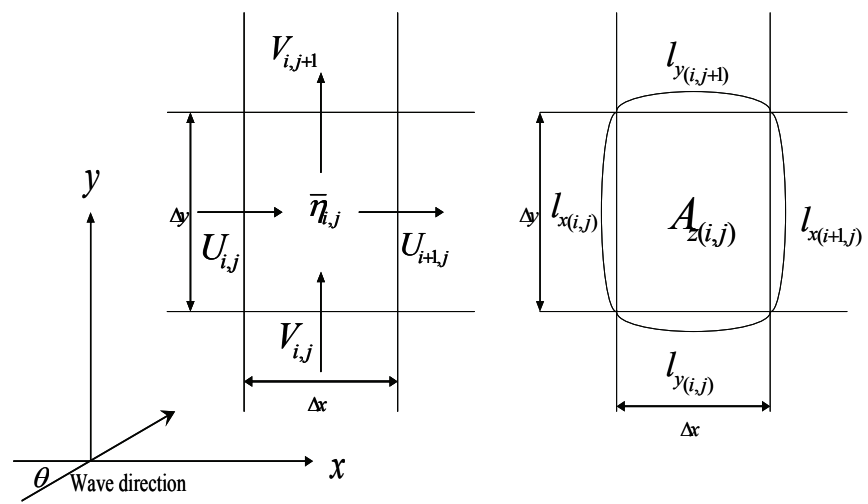

Fig. 1 Coordinate system and definition of variables and fractions.

\section{Sediment transport rate module}

The total sediment transport rates in the cross-shore and longshore directions are defined as the sum of the bed load $\left(q_{b x}, q_{b y}\right)$ and suspended load $\left(q_{s x}, q_{s y}\right)$ :

$q_{x}=q_{b x}+q_{s x}, \quad q_{y}=q_{b y}+q_{s y}$

The bed loads are determined by

$q_{b x}=A_{c}\left(u_{*}{ }^{2}-u_{*_{c}}{ }^{2}\right) U / g, q_{b y}=A_{c}\left(u_{*}{ }^{2}-u_{*_{c}}{ }^{2}\right) V / g$

where, $A_{c}$ is the dimensionless coefficients. $u_{*}$ is the friction velocity. $u_{*_{c}}$ is the critical friction velocity. $A c$ is given by a function of median diameter, $d_{50}$. The friction velocity $u *$, which presented by Sawaragi et al. (1985), was used in order to take account of the interaction of waves and steady currents. The suspended sediment transport rates were determined by multiplying the local current velocities and sediment concentrations. The suspended sediment transport rates are expressed as:

$q_{s x}=\alpha C U(\bar{\eta}+h), q_{s y}=\alpha C V(\bar{\eta}+h)$

where, $\alpha$ is the dimension-less coefficient. The depthaveraged concentration $C$ was determined by solving the twodimensional advection diffusion equation for the concentration of suspended load, as given by: 


$$
\begin{aligned}
\frac{\partial C}{\partial t}+U \frac{\partial C}{\partial x}+V \frac{\partial C}{\partial y} & =\frac{\partial}{\partial x}\left(\varepsilon_{s} \frac{\partial C}{\partial x}\right) \\
& +\frac{\partial}{\partial y}\left(\varepsilon_{s} \frac{\partial C}{\partial y}\right)+\frac{P-w_{f} C}{\bar{\eta}+h}
\end{aligned}
$$

where, $P$ is the sediment pick-up rate based on the van Rijn model (van Rijn, 1985; Buttolph et al., 2006). $\varepsilon_{s}$ is the diffusion coefficient of sand, which was estimated from a function of bottom friction velocities and steady current velocities. The pick-rate $P$ was modified as:

$P=A d_{50}\left(\frac{\tau_{s, \max }-\tau_{c r}}{\tau_{c r}}\right)^{1.5} d_{*}^{-0.3} \times w_{f}$

where, $A$ is the dimensionless coefficient. $d_{50}$ is the median diameter of sand particles. $\tau_{s, \max }$ is the bottom shears tress due to waves and currents. $\tau_{c r}$ is the critical bottom shear stress. $w_{f}$ is the settling velocity of sand, which is estimated by the Rubey formula.

\section{Water depth change module}

The changes in bottom elevation were calculated using the continuity equation of sediment transport rate proposed by Watanabe et al. (1986). The profile changes in the run-up region, namely shoreline changes, were also determined from the continuity equation. The sediment transport rate in the run-up region was determined by extrapolating from one at a reference point (Kuroiwa et al., 2004). The new bottom topography was fed back into the hydrodynamic and sediment transport computations.

\section{COMPUTED RESULTS FOR NEARSHORE CURRENT FIELD}

Firstly, three model tests for nearshore currents around the coastal structures such as groin, river mouth and large scale cusp bathymetries were conducted. The computed results using the FAVOR method were compared with the stair-step boundaries.

\section{A coastal structure}

The significant wave height and period were set to $2.0 \mathrm{~m}$ and $5.0 \mathrm{~s}$, respectively. Wave direction at the offshore boundary was 20 degrees. The bottom slope was 1/50. Fig. 2(a) shows the computed nearshore current field with the FAVOR method. A clockwise circulation flow was reproduced behind the coastal structure. Comparing with the computed result using stair-step grid, as shown in Fig. 1(b), it was found that the current vectors along the breakwater computed by FAVOR method are smooth and slightly higher in magnitude.

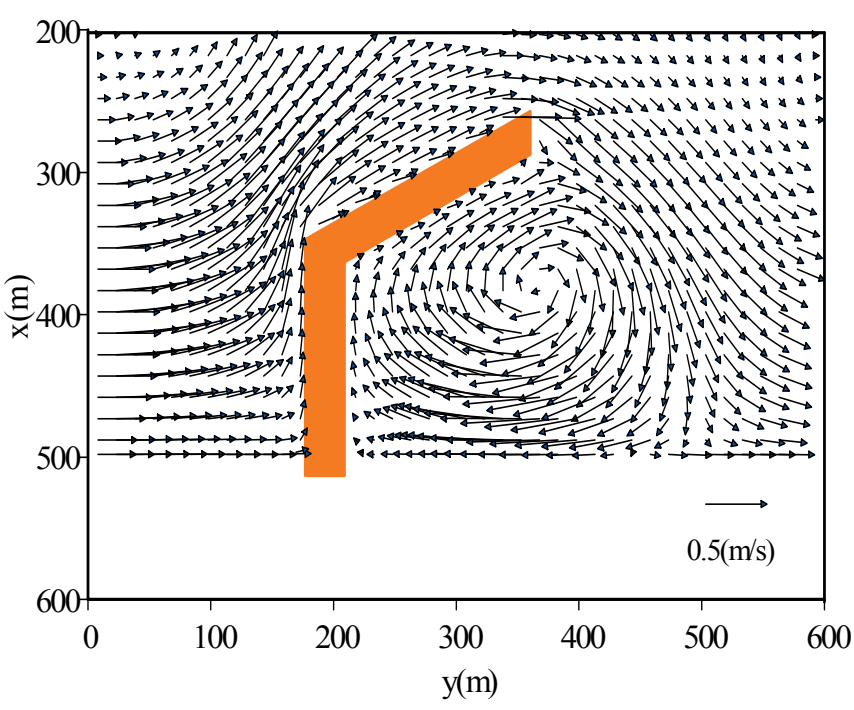

(a) FAVOR method.

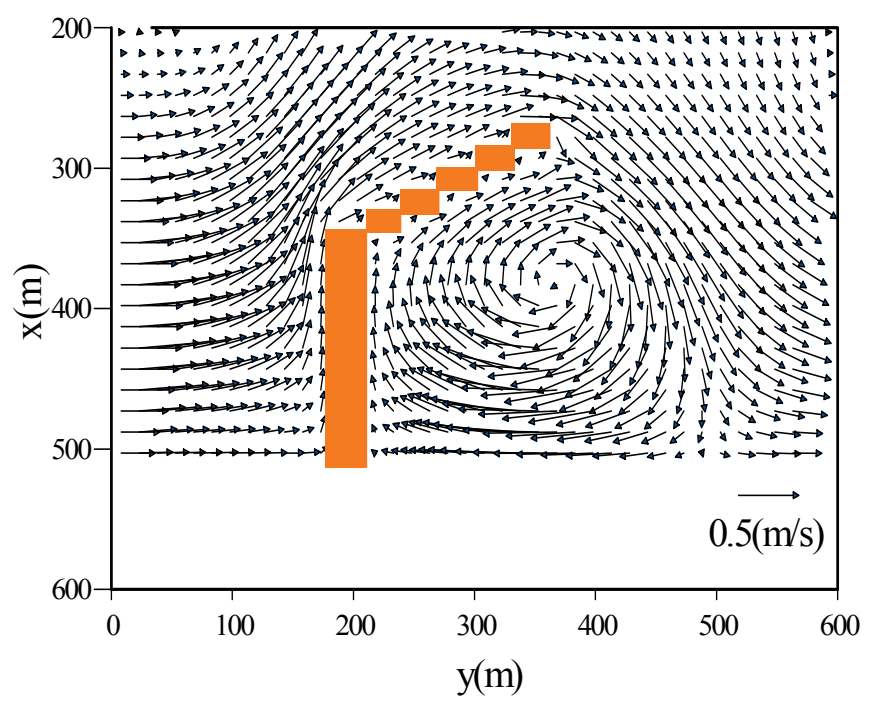

(b) Stair-step boundary.

Fig. 2 Nearshore current field around a coastal structure for (a) FAVOR method, and (b) Stair-step boundary.

\section{A river channel with river mouth}

The significant wave height and period were $1.0 \mathrm{~m}$ and $7.0 \mathrm{~s}$, respectively. The river flow velocity at the up-stream boundary was set at $0.1 \mathrm{~m} / \mathrm{s}$. Figs. 3(a) and 3(b) show the computed results for the FAVOR method and stair-step grid, respectively. From these figures, it was confirmed that the discrepancy of the results without the FAVOR method is very clear. The current velocities near side walls in the river channel were smoothly computed. The values of the computed velocities by the FAVOR method around the river mouth were higher than those with step-stair. These computed results indicate that the presented model with the FAVOR method is very useful. 


\section{A bathymetry with cusp}

The nearshore current field on a bathymetry with cusp was computed as shown in Fig. 4. The wave length of cusp was $400 \mathrm{~m}$ in the alongshore direction. The wave height and period were set to $1.5 \mathrm{~m}$ and $7.0 \mathrm{~s}$, respectively. The wave direction was 20 degrees. From Fig. 4, it was found that the longshore current was generated and a clockwise circulation at the left side on the horn part of the cusp was also generated. The magnitude and direction of current vectors near shoreline computed by using the FAVOR method are different from the computed result with the stair-step boundaries. It was confirmed that the FAVOR method can apply to the computation of nearshore current near the shoreline on the cusp bathymetry.

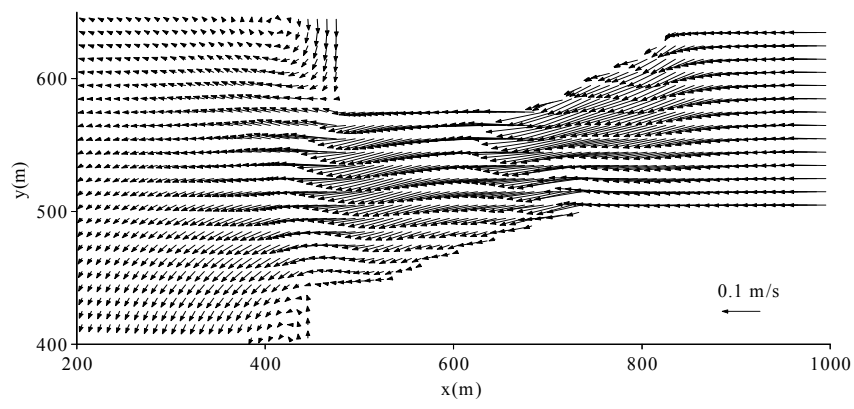

(a) FAVOR method.

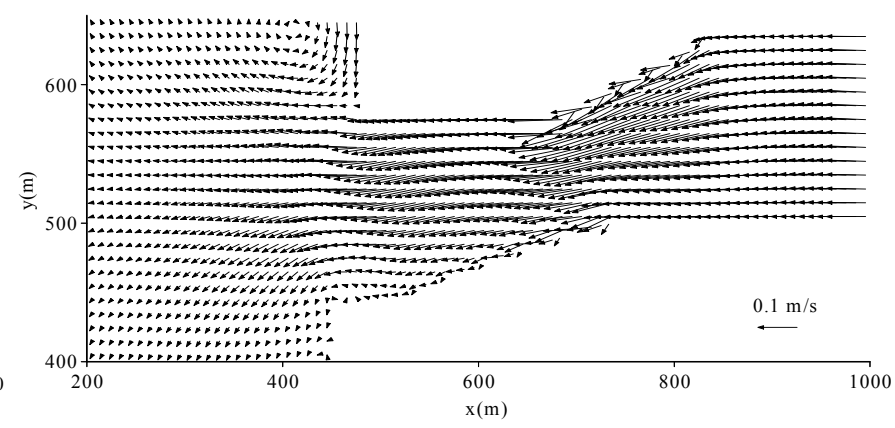

(b) Stair-step boundary.

Fig. 3 Current field in a river channel and river-mouth for (a) FAVOR method, and (b) Stair-step boundary.

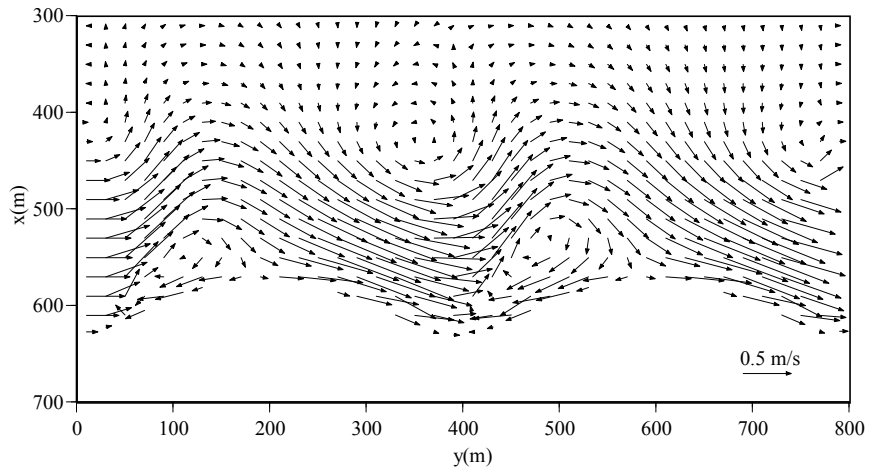

(a) FAVOR method.

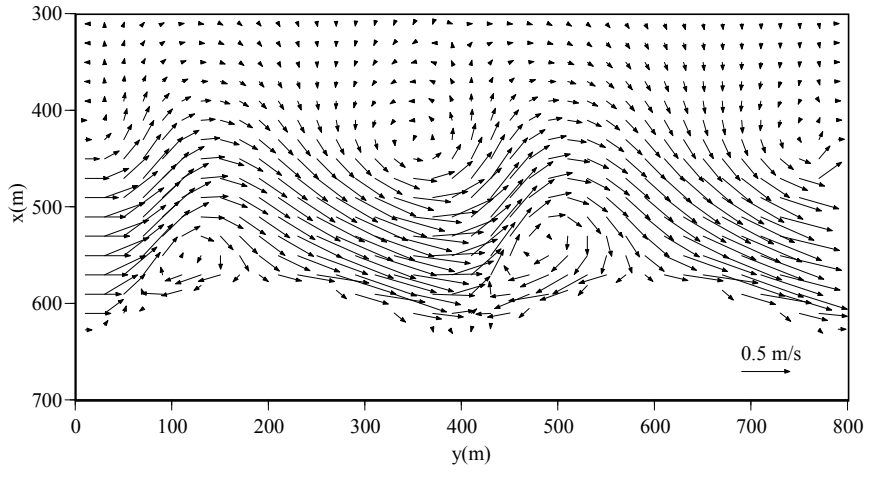

(b) Stair-step boundary.

Fig. 4 Nearshore current field on a bathymetry with cusp for (a) FAVOR method, and (b) Stair-step boundary.

\section{COMPUTED RESULTS FOR A 3D BEACH EVOLUTION}

Two model tests for the 3D morphodynamic around detached breakwater and groins were performed. Furthermore, the model was applied to the tombolo formation due to the construction of the offshore structure in the field site.

\section{Model tests for a 3D beach evolution}

Secondly, model tests associated with (i) a breakwater with the length of $120 \mathrm{~m}$, and (ii) two groins with the length of $100 \mathrm{~m}$, were carried out. The domain of computation in the two tests was covered an area of $600 \mathrm{~m}$ in the cross-shore direction and $800 \mathrm{~m}$ in the longshore direction. The beach slope was $1 / 50$. The beach evolution after 20 days was simulated. The wave height and period at the offshore boundary were set at $1.5 \mathrm{~m}$ and $7.0 \mathrm{~s}$, respectively. In the case of the breakwater, two cases with the wave direction of 0 degree and 20 degrees were demonstrated. In the case of two groins, one case with the wave direction of 0 degree was simulated. The hydrodynamic computations were run 20 times to get the final bathymetry. The simulated bathymetries and nearshore current field after 20 days were shown in Figs. 5,6 , and 7. From those computed results, it was confirmed that the presented model can compute the bottom topographical change with the shoreline change. However, 
with progress of time, local circulation occurred and then bottom topography near the shoreline became complex. For the detached breakwater (Figs. 5 and 6), a salient was formed with normal and oblique incident waves. For the two groins

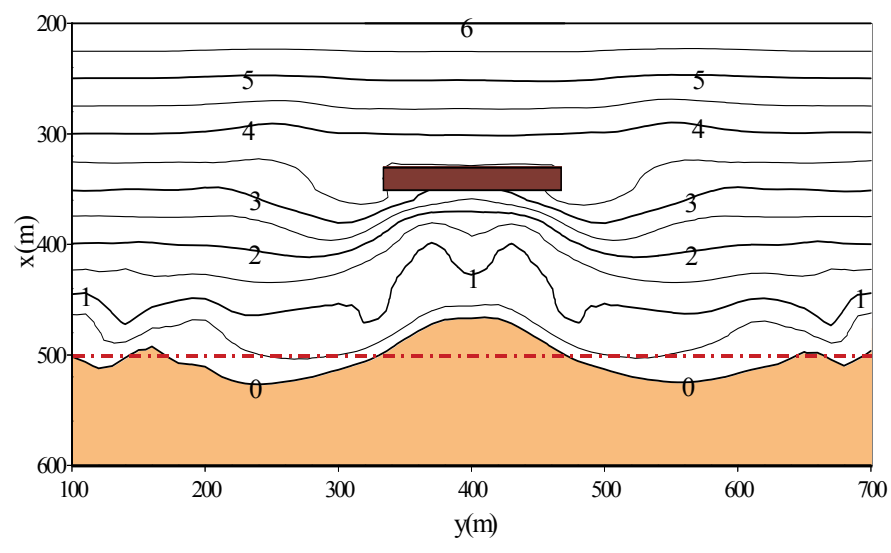

(a) Bathymetry.
(Fig. 7), although the generation of local circulation flow was remarkable, the shoreline change between two groins was qualitatively reproduced.

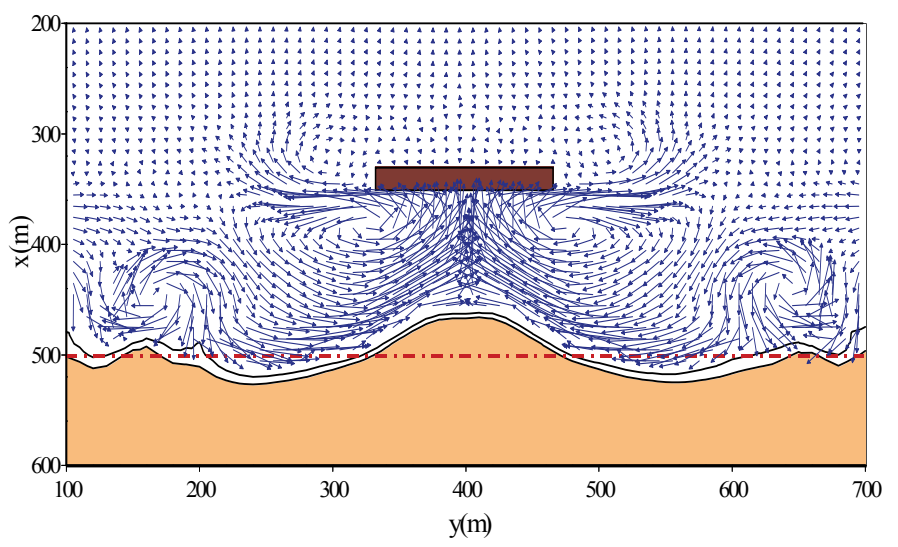

(b) Nearshore current.

Fig. 5 Computed results after 20 days around a detached breakwater with the length of $100 \mathrm{~m}\left(H_{1 / 3}=1.5 \mathrm{~m}, T_{1 / 3}=7.0 \mathrm{~s}, \theta=0^{\circ}\right)$.

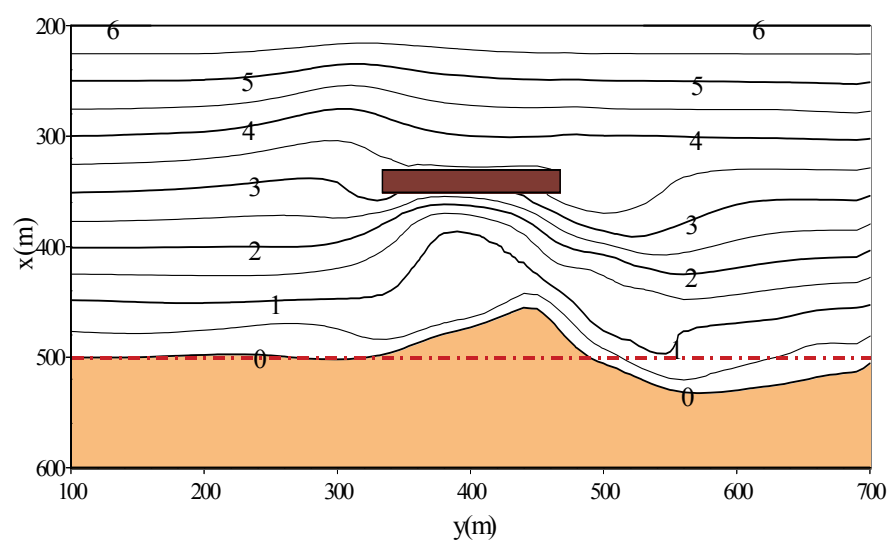

(a) Bathymetry.

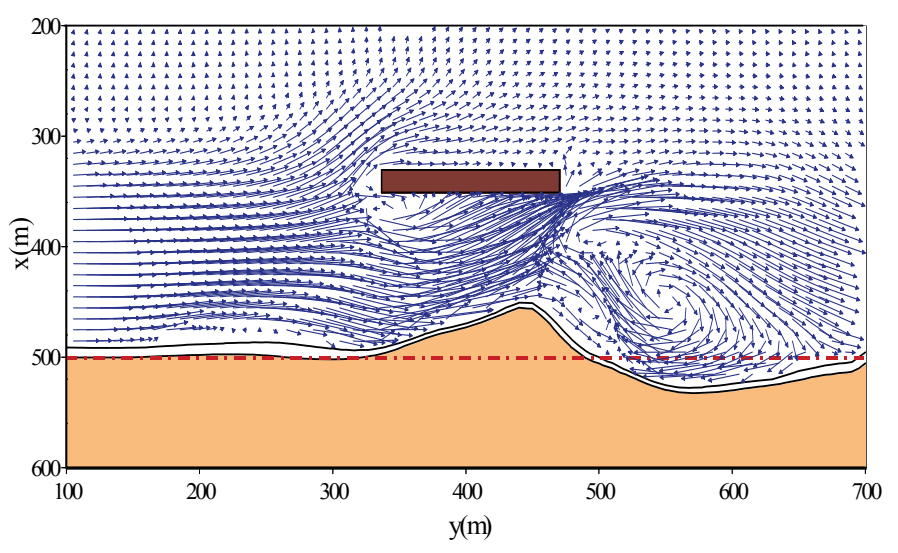

(b) Nearshore current.

Fig. 6 Computed results after 20 days around a detached breakwater with the length of $100 \mathrm{~m}\left(H_{1 / 3}=1.5 \mathrm{~m}, T_{1 / 3}=7.0 \mathrm{~s}, \theta=20^{\circ}\right)$.

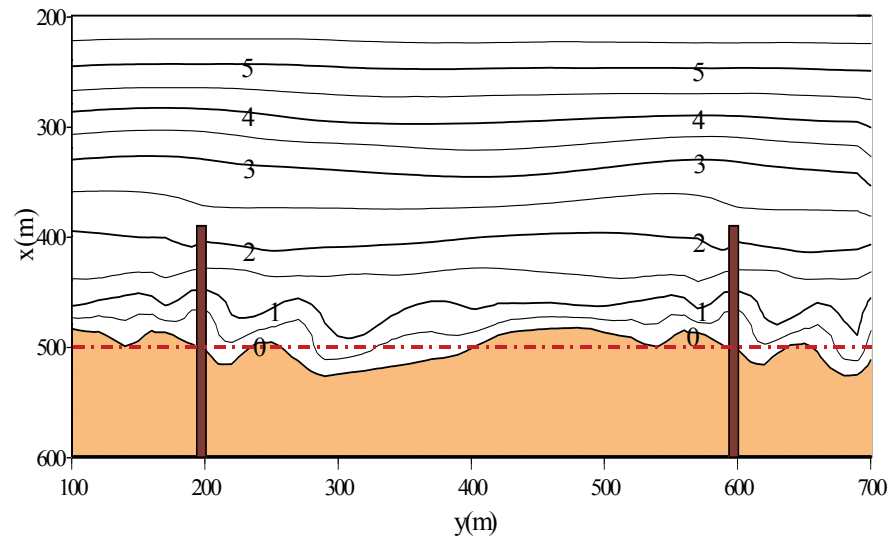

(a) Bathymetry.

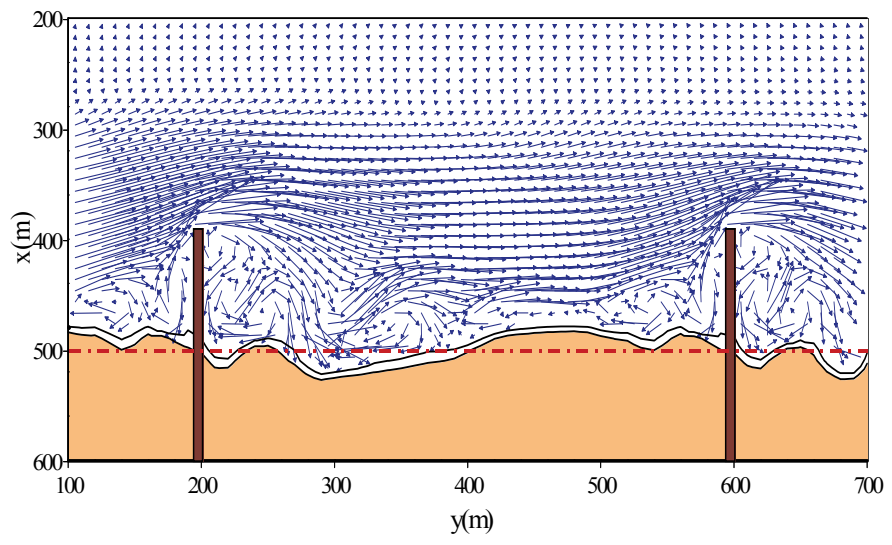

(b) Nearshore current.

Fig. 7 Computed results after 20 days around two groins with the length of $100 \mathrm{~m}\left(H_{1 / 3}=1.5 \mathrm{~m}, T_{1 / 3}=7.0 \mathrm{~s}, \theta=20^{\circ}\right)$. 


\section{Comparison of the field measurement}

Finally, the model was applied to the beach evolution around the offshore-type fishing port, the Kunnui port, located in Hokkaido, Japan (Kawaguchi et al., 1994). The Kunnui fishing port was planned in 1985 and completed in 1994. The tombolo was rapidly formed behind the port within one year (1989 to 1990). In this study, the beach evolution from 1989 to 1990 was used to verify the present model. The time variation of wave data input at the offshore boundary was set as shown in Fig. 8. In order to predict the beach evolution, the significant wave height less than $0.75 \mathrm{~m}$ was omitted and the waves for 112 days were taken into account, because the small waves did not contribute in the beach evolution. The computations of the wave and current models were roughly repeated 10 times to reach 1 year. The computed wave height distribution and nearshore current field on the bathymetry after 1 year are shown in Fig. 9. The comparison of bathymetry after 1 year between the computed and measured results is shown in Fig. 10. From this comparison, although the depth contour lines of $1 \mathrm{~m}, 2 \mathrm{~m}$ and $3 m$ were advanced to the offshore direction due to the circulation behind the fishing port, the computed shoreline change is smaller than that of the field measurement.

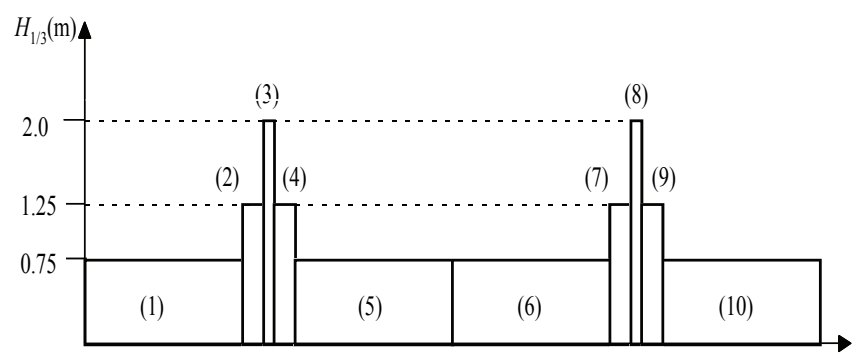

\begin{tabular}{|c|c|c|c|}
\hline Step & $t$ (days) & $H(\mathrm{~m})$ & $T(\mathrm{~s})$ \\
\hline (1),(5),(6),(10) & 24.8 & 0.75 & 7 \\
\hline (2),(4),(7),(9) & 2.1 & 1.25 & 8 \\
\hline (3),(8) & 0.2 & 2 & 10 \\
\hline
\end{tabular}

Fig. 8 Time variation of wave height and period input at offshore boundary.

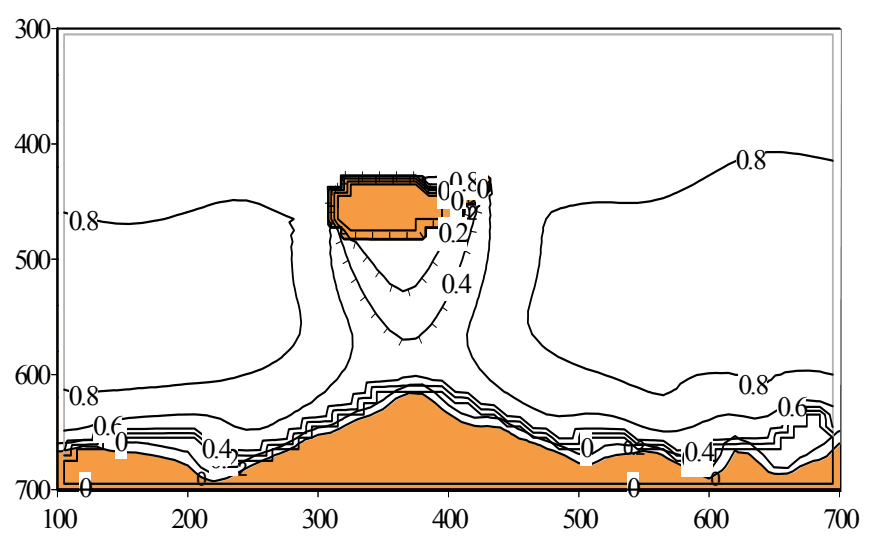

(a) Significant wave height.

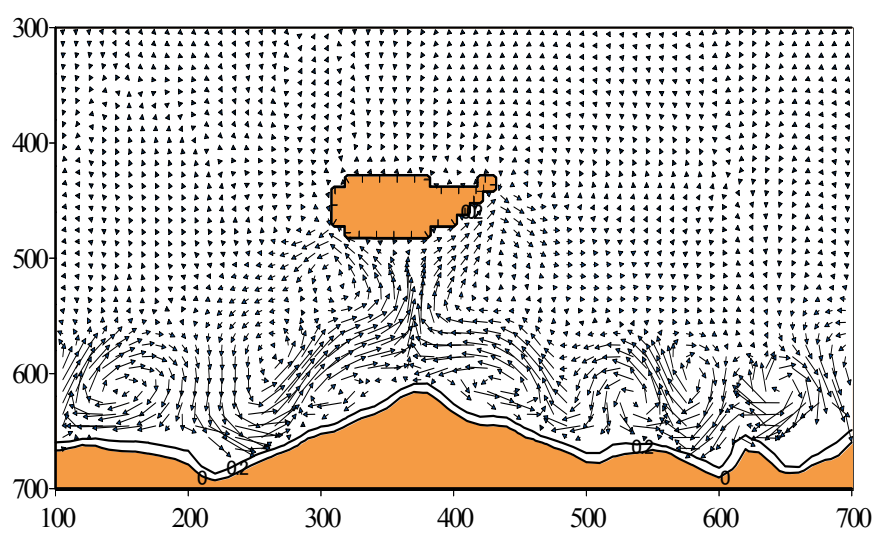

(b) Nearshore current.

Fig. 9 Computed results of the significant wave height and nearshore currents after 1 year.

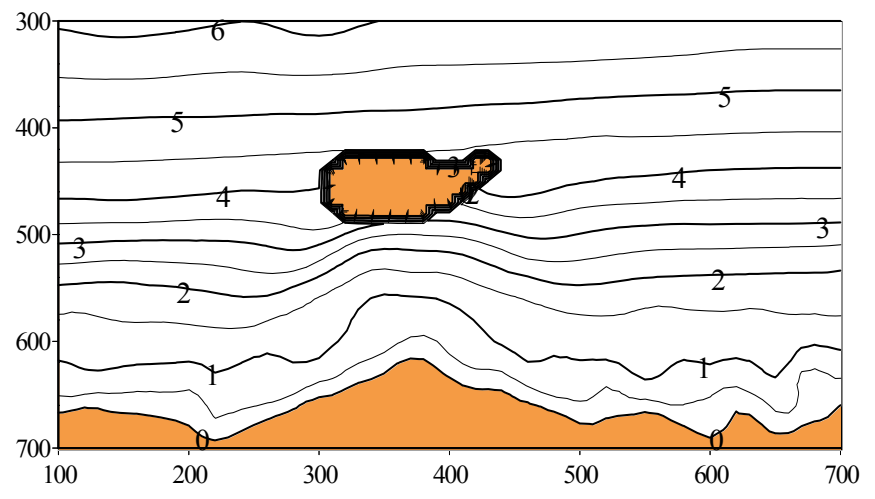

(a) Computed bathymetry.

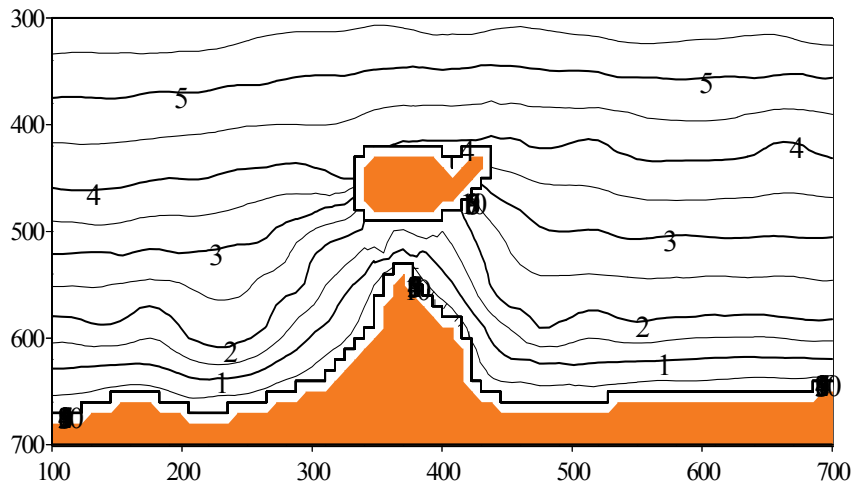

(b) Measured bathymetry.

Fig. 10 Comparison between (a) computed bathymetry against measurements after 1 year, and (b) measured bathymetry. 


\section{CONCLUSIONS}

The presented model uses the Fractional Area/Volume Obstacle Representation method to represent the complex boundaries containing the flow. By using the FAVOR method, the boundaries of the domain (including any obstacles in the flow) can evolve in time and thus can be used to simulate the changes of the seafloor or of the position and orientation of obstacles.

The simulations presented demonstrate the potential of the numerical methods to investigate a wide range of practical problems in coastal engineering. Firstly, the performance of the nearshore current model with the FAVOR method was investigated for breakwater, river mouth, and cusp. The nearshore current model using the FAVOR method is useful to predict steady currents in the vicinity of coastal structures. Secondly, the presented 3D beach evolution model was applied to the morphodynamics around the detached breakwater and two groins. Finally, the verification of the model was carried out by comparing the numerical model results against the field measurement. It was found, in the computation of $3 \mathrm{D}$ beach evolution with the shoreline changes, that the presented model can qualitatively compute the shoreline changes. From the comparison against the field measurement, the magnitude of the computed salient was different from the measured one. Possible some causes of the discrepancy are due to the estimation of total sediment transport rates.

Further development concern the estimation of total sediment transport is needed to improve the model prediction; this work will help with calibrating and validating the model.

\section{REFERENCES}

Chen, Z.H. Fang, H. and Liu, B., 2007. Numerical simulation of wind-induced motion in suspended sediment transport. Journal of Hydrodynamics, 19(6), pp. 698-704.
Hirt, C.W. and Sicilian, J.M., 1985. A Porosity Technique for the Definition of Obstacles in Rectangular Cell Meshes. Proc. of the 4th International Conference on Ship Hydrodynamics, Washington D.C., September 1985.

Kawaguchi, T. Hashimoto, O. Mizumoto, T. and Kmata, A., 1995. Construction of offshore fishing port for prevention of coastal erosion. Proc. of $24^{\text {th }}$ International Conference on Coastal Engineering, ASCE, 2, pp. $1197-$ 1211.

Kuroiwa, M. Kamphuis, J.W. Kuchiihshi, T. Matsubara, Y. and Noda, H., 2004. Medium-term Q-3D coastal area model with shoreline change around coastal structures. Proc. of $29^{\text {th }}$ International Conference on Coastal Engineering, ASCE, 2, pp. 2194-2207.

Kuroiwa, M. Kuchiishi, T. Kato, K. Sunagawa, S. and Matsubara, Y., 2008. Applicability of coastal area model to morphodynamics around river mouth. Proc. of $31^{\text {st }}$ International Conference on Coastal Engineering, ASCE, 3, pp.2218-2230.

Mase, H., 2001. Multi-directional random wave transformation model based on energy balance equation. Coastal Engineering Journal, 43(4), pp. 317-337.

Sawaragi, T. Lee, J.S. and Deguchi, I., 1985. A new model for prediction of beach deformation around river mouth. Proc. of International Symposium on Ocean Space Utilization, pp. 229-236.

Van Rijn, L., 1985. Two-dimensional vertical mathematical model for suspended transport by currents and waves. Report S488-IV, Delft Hydraulics.

Watanabe, A. Maruyama, K. Shimizu, T. and Sakakiyama, T., 1986. A numerical prediction model of threedimensional beach deformation around a structure. Coastal Engineering, 29, pp.179-194. 